Article

\title{
Synergetic Effect of Calcium Doping on Catalytic Activity of Manganese Ferrite: DFT Study and Oxidation of Hydrocarbon
}

\author{
Zahoor Iqbal ${ }^{1}$, , Saima Sadiq ${ }^{1,2, *}$, Muhammad Sadiq $1, * \mathbb{C}$, Muhammad Ali ${ }^{1,3}$, Khalid Saeed ${ }^{4}$, \\ Najeeb Ur Rehman ${ }^{1}$, Mohammad Ilyas ${ }^{5,6}$, Saif Ullah ${ }^{7}$, Saeed Ullah Jan ${ }^{1,7}$, Iftikhar Ahmad ${ }^{7}$ and \\ Mian Hussain Shah ${ }^{1}$ \\ 1 Department of Chemistry, University of Malakand, Chakdara 18800, Pakistan; \\ arhamiqbal2017@gmail.com (Z.I.); nrnajeeb@yahoo.com (N.U.R.); saeedsimaab@gmail.com (S.U.J.); \\ hussainshah697@gmail.com (M.H.S.); muhammadali@unist.ac.kr (M.A.) \\ 3 School of Energy and Chemical Engineering, Ulsan National Institute of Science and Technology, \\ Ulsan 44919, Korea \\ 4 Department of Chemistry, Bacha Khan University, Charsadda 24420, Pakistan; khalidkhalil2002@yahoo.com \\ 5 Chemical and Life Sciences, Qurtuba University of Science \& Information Technology, Peshawar 25000, \\ Pakistan; mohilyas52@yahoo.com \\ 6 National Center of Excellence in Physical Chemistry, University of Peshawar, Peshawar 25120, Pakistan \\ 7 Center for Computational Materials Science, University of Malakand, Chakdara 18800, Pakistan; \\ saifullah246@gmail.com (S.U.); ahma5532@gmail.com (I.A.) \\ * Correspondence: sadiq@uom.edu.pk (M.S.); saima@knu.ac.kr (S.S.)
}

Received: 22 February 2020; Accepted: 10 March 2020; Published: 23 April 2020

\begin{abstract}
Manganese ferrite $\left(\mathrm{MnFe}_{2} \mathrm{O}_{4}\right)$ and calcium-doped manganese ferrite $\left(\mathrm{Ca}-\mathrm{MnFe}_{2} \mathrm{O}_{4}\right)$ were synthesized, characterized, and tested for oxidation of hydrocarbons $(\mathrm{CH})$ in a self-designed gas blow rotating (GBR) reactor. The uniformly sized and thermally stable $\mathrm{MnFe}_{2} \mathrm{O}_{4}$ nanoparticles (molar ratio, 1/284.5) showed a reasonable catalytic activity (productivity: $366.17 \mathrm{mmolg}^{-1} \mathrm{~h}^{-1}$ ) with $60 \%$ selectivity at $80^{\circ} \mathrm{C}$, which was further enhanced by calcium doping (productivity: $379.38 \mathrm{mmolg}^{-1} \mathrm{~h}^{-1}$ ). The suspicious behavior of Ca- $\mathrm{MnFe}_{2} \mathrm{O}_{4}$ was disclosed experimentally and theoretically as well.
\end{abstract}

Keywords: $\mathrm{MnFe}_{2} \mathrm{O}_{4} ; \mathrm{Ca}-\mathrm{MnFe}_{2} \mathrm{O}_{4} ; \mathrm{DFT}$; oxidation; hydrocarbon

\section{Introduction}

In recent decades, ferrite has gained extensive attention due to its high degree of specific resistivity, high dielectric constant, magnetic coactivity (soft/hard ferrites) and crystal structure (spinel/hexagonal) [1-9]. Similarly, doped ferrites are of great interest due to their frequent use in many scientific and technological areas, including catalysis [1-10]. Metal doping alters the electronic and magnetic properties; therefore, high-quality magnetic nanoparticles with excellent catalytic properties can be prepared by doping metals on ferrites because it increases magnetic saturation [9-12]. Spinel ferrite, especially $\mathrm{MnFe}_{2} \mathrm{O}_{4}$, has attracted the attention for its wide applicability in electronic devices [13], catalysis [14,15], magnetic storage [16], microwave [17], biosensors [18], drug delivery [19], magnetic resonance imaging [20] and ferrofluids [21]. $\mathrm{MnFe}_{2} \mathrm{O}_{4}$ has soft magnetic behavior with brilliant structural stability. On the virtue of magnetic properties, these nanoparticles can be easily removed and recycled from the reaction mixture. However, the catalytic ability of these ferrites is due to the presence of $\mathrm{Fe}$, which is capable of good redox properties with a good structural stability. Spinel ferrites, like $\mathrm{MnFe}_{2} \mathrm{O}_{4}$ have been applied as an efficient catalyst for dehydrogenation reaction, fenton reaction, 
oxidation, reforming of ethanol [22], dye degradation [23], nitrogen oxide reduction [24], ammonia oxidation [25], incineration of isopropyl [26], ozonation of 4-chlorophenol [27] and carbon dioxide-based reactions [28]. $\mathrm{MnFe}_{2} \mathrm{O}_{4}$ has been reported for the oxidation of alcohol without solvent, as well as in organic solvent using t-butyl hydroperoxide and $\mathrm{H}_{2} \mathrm{O}_{2}$, achieving productivity values of 32.95 and $2.78 \mathrm{mmolg}^{-1} \mathrm{~h}^{-1}$, respectively $[29,30]$. Keeping in view the capability of spinel ferrites $\left(\mathrm{MnFe}_{2} \mathrm{O}_{4}\right)$ as catalysts, they challenge researchers to explore and modify their magnetic and catalytic performance for future industrial demands. Moreover, the oxidation of $\mathrm{CH}$ has many applications, e.g., as a solvent, homogenizer, stabilizer in soaps/detergents, plasticizer in the surface-coating industry, pesticides and pharmaceutical products [31-34]. Usually, oxidation/dehydrogenation of $\mathrm{CH}$ is performed in two steps: the conversion of $\mathrm{CH}$ without a catalyst in the presence of molecular oxygen to alkylhydroperoxide (CHHP), followed by the synthesis of products from alkylhydroperoxide with a homogeneous cobalt (Co (II)) catalyst. The drawback of this process is not only low percent conversion with poor selectivity to CHHP [31], but also the laborious and cost-effective recycling of hydrocarbon, the recovery of the Co (II) catalyst from the reaction medium and the production of salts, all of which make the process impractical for industrial use [34]. Therefore, extensive research has been carried out to replace this conventional process with green alternative.

In this scenario, heterogeneous catalysis is a key to rectifying the drawbacks in the large-scale production of alcohol/ketone $(\mathrm{CHOH} / \mathrm{RCOR})$ from the oxidation of $\mathrm{CH}$. Selective production of $\mathrm{CHOH} / \mathrm{RCOR}$ through heterogeneously catalyzed oxidation of $\mathrm{CH}$ using supported noble metals is the most popular and convenient method, but the high price and leaching of noble metals into the reaction medium create problems for large-scale production [35-41]. Transition metal-based catalysts, such as $\mathrm{Cr}, \mathrm{Co}, \mathrm{Cu}, \mathrm{Ta}$, and $\mathrm{Nb}$ proved to be efficient catalysts; however, the use of solvents $[35,36]$ and expensive oxidant [37] in these catalytic systems make their use impractical. Several catalysts containing metals, metal alloys, metal nanoparticles, and polymers supported on alumina, silica, MCM-41, and hydroxyapatite have been utilized in the absence of solvents with oxygen as the sole oxidant [33,37-41]. These catalysts have few limitations, such as loss of activity, poor selectivity, low sensitivity, and high cost. Therefore, it is desired to introduce ecofriendly catalytic system following the principles of green chemistry.

To the best of our knowledge, the schizophrenic effect of calcium doping on the catalytic and magnetic properties of $\mathrm{MnFe}_{2} \mathrm{O}_{4}$ for oxidation of $\mathrm{CH}$ in a solvent-free system has not been reported. Thus, exploring the dramatic change in the behavior of catalysts, experimentally and theoretically, may be an interesting issue.

\section{Experimental}

The chemicals and reagents that were used in this study were of high purity grade (supplier: Sigma-Aldrich \& Merck, Karachi, Sindh, Pakistan) and were used without any further purification. Gases like oxygen and nitrogen were supplied by BOC, Pakistan Ltd. For the removal of traces from the gases, specific filters (PerkinElmer: safe glass moisture trap, part number N930-1193 and PerkinElmer: gas line filter, part number N930-1178) were used.

\subsection{Synthesis of the Catalysts}

Iron oxide, $\mathrm{MnFe}_{2} \mathrm{O}_{4}$, and $\mathrm{Ca}-\mathrm{MnFe}_{2} \mathrm{O}_{4}$ nanoparticles were prepared by the precipitation/ co-precipitation method with modifications, as reported in the literature [42]. Briefly, solutions of $\mathrm{FeCl}_{3} \cdot 6 \mathrm{H}_{2} \mathrm{O}(0.2 \mathrm{M}), \mathrm{MnCl}_{2} \cdot 4 \mathrm{H}_{2} \mathrm{O}(0.1 \mathrm{M})$, and $\mathrm{Ca}\left(\mathrm{NO}_{3}\right)_{2} \cdot 4 \mathrm{H}_{2} \mathrm{O}(0.05 \mathrm{M})$ were prepared in deionized water. The individual solution and/or mixture of solutions was titrated against $3 \mathrm{M}$ solution of $\mathrm{NaOH}$ (pH 9), which was preheated to $95^{\circ} \mathrm{C}$. The mixture was aged for $2 \mathrm{~h}$ at constant stirring and then allowed to cool down at room temperature. The precipitates formed were separated by centrifugation, washed several times until they reached a neutral $\mathrm{pH}$, and dried for ten hours in an oven at $80^{\circ} \mathrm{C}$. The resulting nanoparticles were crushed to a fine powder and stored in a desiccator. 


\subsection{Characterization of Catalysts}

The catalysts were characterized by Transmission Electron Microscopy (TEM) and Scanning Electron Microscopy (SEM, JSM 5910, Jeol, Japan). The elemental analysis of samples was investigated by Energy Dispersive X-ray Spectroscopy (EDX) (JSM 5910, JEOL, Japan). The phase of the samples was determined by an X-ray Diffractometer (D/Max-II, Rigaku, Japan) with the radiation source CuK $\alpha$ with $\lambda=0.15418 \mathrm{~nm}$ and an operating voltage of $40 \mathrm{kV}$, in the $2 \theta$ range of $10^{\circ}-70^{\circ}$ at a step size of $0.05^{\circ}$. Thermogravimetric analysis of the samples was investigated using a Thermal Gravimetric Analyzer (TGA, PerkinElmer, USA). The Fourier Transform Infrared Spectrometer (FT-IR) (Prestige 21, Shimadzu, Japan) was used to record the FT-IR spectra of the sample pellets $(1.3 \mathrm{~mm}$ ) with $\mathrm{KBr}$ (spectrum range $\left.500-4000 \mathrm{~cm}^{-1}\right)$.

\subsection{DFT Study of the Catalyst}

In this work density functional theory calculations were performed using the Full Potential Linearized Augmented Plane Wave method (FP-LAPW) implemented in Wien2k code [43]. To deal with exchange and correlation, energy-generalized gradient approximations [44] are used for electronic properties. In the FP-LAPW method, the wave function for potential and charge density expansion is composed of the combination of radial functions multiplied by spherical harmonics inside the atomic radii and plan waves in the interstitial region. The cut-off value for the planned wave $R M T \times K_{\max }=8$ is selected, while the charge density is Fourier-expanded up to $G_{\max }=14$ (Ryd). For the integration of the Brillouinzone, we used $7 \times 7 \times 7 \mathrm{k}$-point. The self-consistent convergence is achieved up to $0.5 \mathrm{mRy} /$ Bohr.

\subsection{Oxidation Reaction}

A total of $0.1849 \mathrm{~mol}$ of cyclooctane $\left({ }^{\mathrm{a}} \mathrm{CH}\right)$ or cyclohexane $\left({ }^{b} \mathrm{CH}\right)$ or cyclohexene $\left({ }^{c} \mathrm{CH}\right)$ and the catalyst $\left(6.5 \times 10^{-4} \mathrm{~mol}\right)$ were loaded into a self-designed gas blow rotating (GBR) reactor. The temperature of the reactor was maintained through heating tapes and a temperature controller (Digi-Sense, ColeParmer, USA). Furthermore, the reaction parameters were set up as desired from the temperature range: $60-80{ }^{\circ} \mathrm{C}$, time: $25-240 \mathrm{~min}$, catalyst: $0.01-0.25 \mathrm{~g}$ and oxygen partial pressure: 50-760 Torr. Iodometric titration with sodium thiosulfate was used for the determination of CHHP in the reaction mixture [45]. The $\mathrm{CHHP}$ was completely converted into $\mathrm{CH}$ by adding an excessive amount of triphenylphosphine $\left(\mathrm{PPh}_{3}\right)$. The amount of acid that was generated in the reaction was titrometrically $(\mathrm{NaOH})$ determined [46]. The exact content (conc.) of alcohol $(\mathrm{COH})$ was determined by deducting the content (conc.) of $\mathrm{CHHP}$, as determined by iodometry from the amount of $\mathrm{COH}$ determined by gas chromatography (GC) analysis (Clarus 580, PerkinElmer, USA) equipped with flame ionization detector (FID), while using a capillary column (cross-linked methyl siloxane capillary column; length: $30 \mathrm{~m}$, ID: $0.32 \mathrm{~mm}$, and film thickness: $0.25 \mu \mathrm{m}$ ), while n-nonane was used as the internal standard. The \% conversion was calculated from initial and final concentrations of $\mathrm{CH}$, although the $\%$ selectivity to the product was determined as a ratio of $\mathrm{COH} / \mathrm{RCOR}$ to the total conversion of the product, from standard calibration curves, as given in the Supporting Information (SI), CH (Figure S1), $\mathrm{COH}$ (Figure S2), and RCOR (Figure S3).

\section{Results and Discussion}

\subsection{Physical Characterization of the Catalysts}

The characterization of Mn-ferrite was performed using various analytical techniques, as given in Figure 1. Figure 1a shows that the Mn-ferrite has uniform, ultra-small spherical structure as distinct entities with some aggregates. Similarly, Figure $1 \mathrm{~b}$, reveals that some of the nanostructures were interconnected with each other, or present in the form of bulbous clusters. The average grain intercept (AGI) method was used to determine the particle size of the nanoparticles ( $30-75 \mathrm{~nm}$ ) which is also reflected from the TEM image. Figure 1c, presents the percent weight of each element as Mn (22\%), 
Fe $(45 \%)$, oxygen $(\sim 28 \%)$, traces of carbon $(9 \%)$, and silicon $(\sim 1 \%)$, while the original energy dispersive $\mathrm{X}$-Ray analysis (EDX) spectra is given in Figure S4.
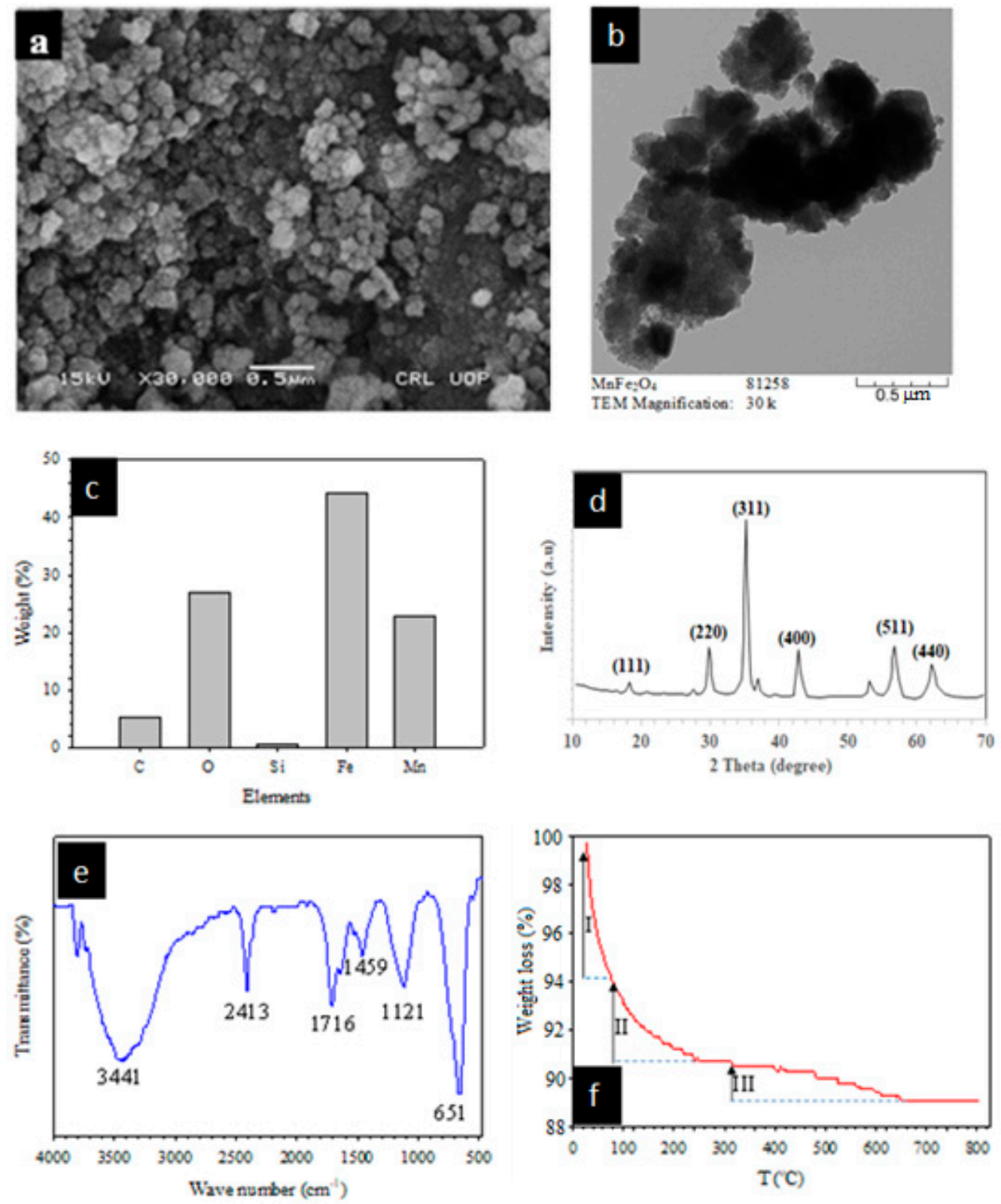

Figure 1. Physical characterization (a) Scanning Electron Microscopy (SEM), (b) Transmission Electron Microscopy (TEM), (c) Energy Dispersive X-ray Spectroscopy (EDX), (d) XRD pattern, (e) Fourier Transform Infrared Spectrometer (FT-IR) spectrum and (f) Thermal Gravimetric Analyzer (TGA) analysis of $\mathrm{MnFe}_{2} \mathrm{O}_{4}$.

Figure $1 \mathrm{~d}$ shows the XRD of Mn-ferrite. The diffractogram consists of different peaks at $2 \theta=$ $17.98^{\circ}, 29.78^{\circ}, 42.51^{\circ}, 53.03^{\circ}, 56.48^{\circ}$ and $61.98^{\circ}$ that are responsible for the cubic spinel structure of Mn-ferrite with crystal planes (111), (220), (311), (400), (511) and (440), respectively. The Mn-ferrite nanoparticles that were prepared by the sol-gel combustion method have similar XRD patterns [27], as observed in the recent study. However, the diffractogram of Mn-ferrite is in close agreement with the International Center for Diffraction Data (JCPDS card No. 10-0319). The Scherrer equation was used to calculate the crystallite size of the Mn-ferrite. The calculated crystallite size $(24 \mathrm{~nm})$ is in close agreement with the reported studies [27]. The variation in the size calculated from XRD and SEM is due to the aggregation of the Mn-ferrite nanoparticles. 
The FT-IR spectrum of $\mathrm{MnFe}_{2} \mathrm{O}_{4}$ is given in Figure 1e. Different bands for functional groups were observed; the band at $3441 \mathrm{~cm}^{-1}$ is due to hydroxyl groups $(\mathrm{OH})$ group residue, while the band at $651 \mathrm{~cm}^{-1}$ is responsible for Fe-O vibration. Similarly, bands at 1459 and $1121 \mathrm{~cm}^{-1}$ are assigned to the $\mathrm{Mn}-\mathrm{O}-\mathrm{Fe}$ bond stretching, while the peaks at 1721 and $2451 \mathrm{~cm}^{-1}$ may be due to the presence of $\mathrm{sp}^{2}$ and sp-hybridized carbon contents. Sahoo \& coworkers [23] prepared Mn-ferrite for the catalytic degradation of dye pollutant. They predicted the FT-IR spectrum for Mn-ferrite, which is in close agreement with our data. Bellusci \& co-workers [46] synthesized albumin-ferrite superparamagnetic nanoparticles by the reverse micelle method to attain high inorganic contents in polymeric materials. They also reported the FT-IR spectrum for Mn-ferrite nanoparticles, which was comparable to our investigation. The $\mathrm{OH}$ group may facilitate and enhance the surface activity of Mn-ferrite [46]. The TGA thermogram of $\mathrm{Mn}$-ferrite that is presented in Figure $1 \mathrm{f}$ shows three different regions for weight loss. First weight loss $(5 \%)$ in the range of $30-100^{\circ} \mathrm{C}$ was due to surface water, while the second weight loss (3\%) was observed in the range of $110-250{ }^{\circ} \mathrm{C}$ due to surface oxygen.

The third observable region was in the range of $300-600{ }^{\circ} \mathrm{C}$ (weight loss of $2 \%$ ) because of bulk oxygen and residual carbon contents. Beyond $600{ }^{\circ} \mathrm{C}$, no more weight loss was observed [23,27,47]. Figure 2 shows the physical characterization of Ca-Mn-ferrite. The SEM image revealed that the particles are in aggregate form (Figure 2a), while the EDX spectra confirmed the presence of Ca doping (Figure $2 b$ ). Similarly, the XRD patterns show few extra peaks that are responsible for $\mathrm{Ca}$ at $2 \theta=29.3^{\circ}, 36.4^{\circ}$ (Figure 2c). The surface areas for Mn-ferrite and Ca-Mn-ferrite were 48.9 and $41.5 \mathrm{~m}^{2} / \mathrm{g}$, respectively. The decrease in surface area is most probably due to the blockage of pores and also the increase in particle size, as presented in Figure 2d. The adsorption/desorption isotherm of both catalysts shows that the pores have narrow bottleneck-like shape, which reflects the mesoporous texture [48].
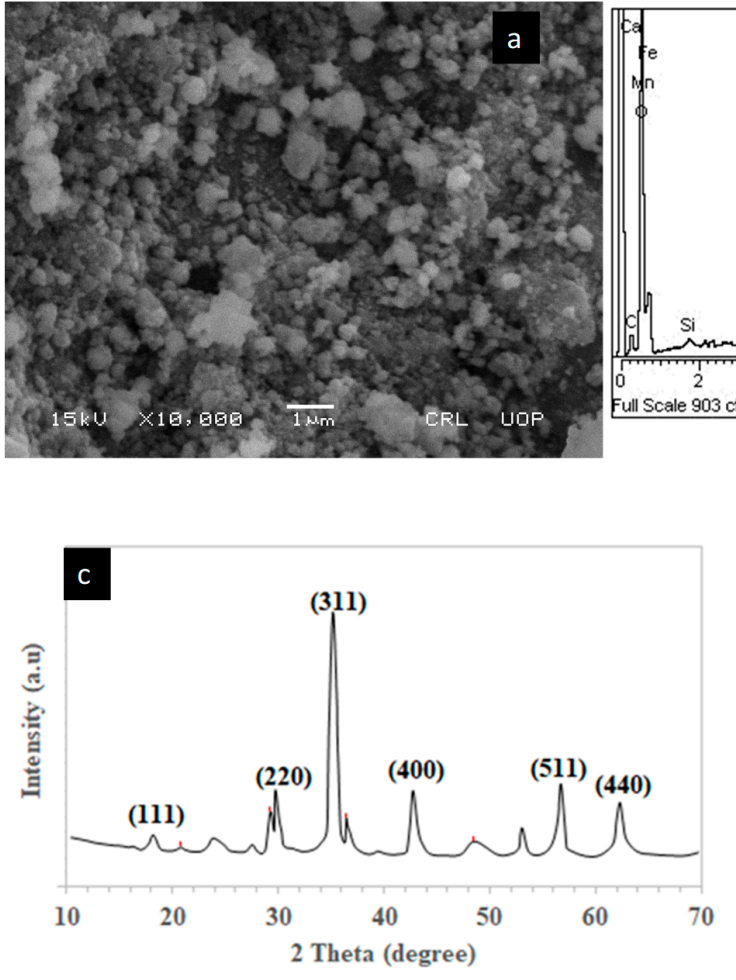

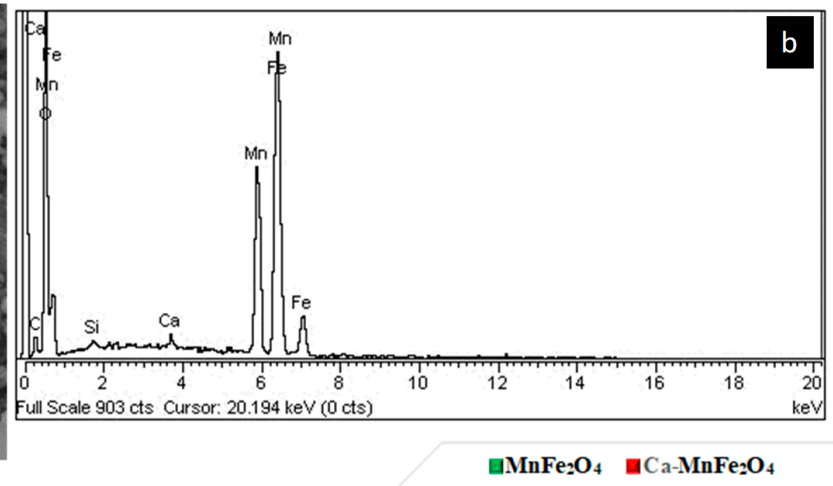

$\mathrm{MnFe}_{2} \mathrm{O}_{4} \quad \mathrm{aCa}-\mathrm{MnFe}_{2} \mathrm{O}_{4}$

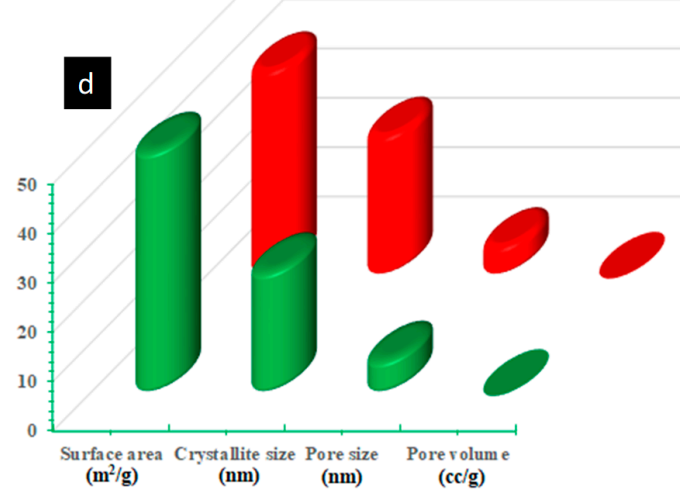

Figure 2. Physical characterization (a) SEM, (b) EDX, (c) XRD pattern of Ca- $\mathrm{MnFe}_{2} \mathrm{O}_{4}$, and (d) surface features of $\mathrm{MnFe}_{2} \mathrm{O}_{4}$ and $\mathrm{Ca}-\mathrm{MnFe}_{2} \mathrm{O}_{4}$.

\subsection{Screening of the Catalyst}

Reaction parameters were optimized for the efficient catalytic activity of magnetic nanoparticles for the green and selective oxidation of $\mathrm{CH}$ to $\mathrm{COH} / \mathrm{RCOR}$, as shown in Scheme 1. 


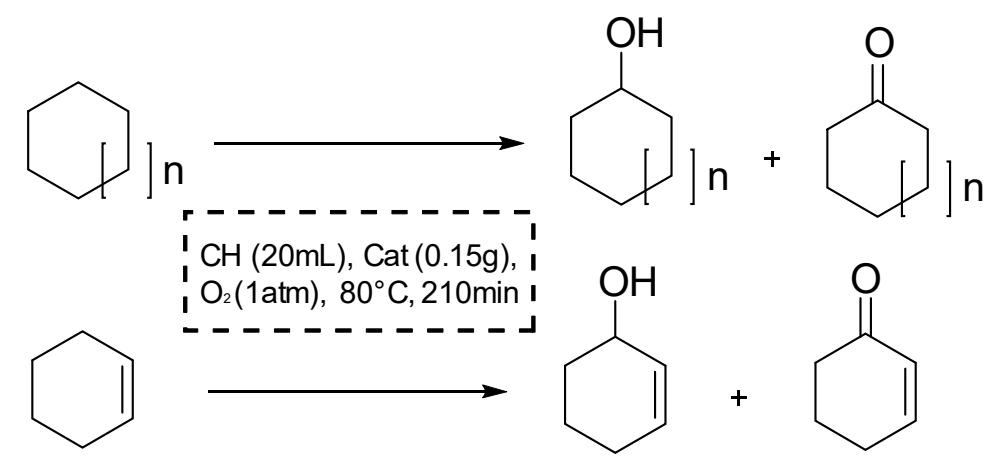

Scheme 1. Oxidation of cyclooctane, cyclohexane, and cyclohexene over $\mathrm{MnFe}_{2} \mathrm{O}_{4}$ and $\mathrm{Ca}-\mathrm{MnFe}_{2} \mathrm{O}_{4}$.

The initial substrate volume has an inverse relation with \% production of $\mathrm{COH} / \mathrm{RCOR}$. The oxidation of $\mathrm{CH}$ conversion to $\mathrm{COH} / \mathrm{RCOR}$ decreases with an increase in the initial volume of $\mathrm{CH}(\mathrm{mL})$, as shown in Figure 3. The observed trend may be attributed to the availability of $\mathrm{CH}$ in large amounts to the surface of Mn-ferrite. However, the reverse trend was observed in \% selectivity, which linearly increases with the increase in the initial substrate volume. Most probably, more oxidation of $\mathrm{CH}$ occurred at a high concentration, instead of the deep oxidation of $\mathrm{COH} / \mathrm{RCOR}$ because of the unavailability of active sites on the surface of the catalyst.

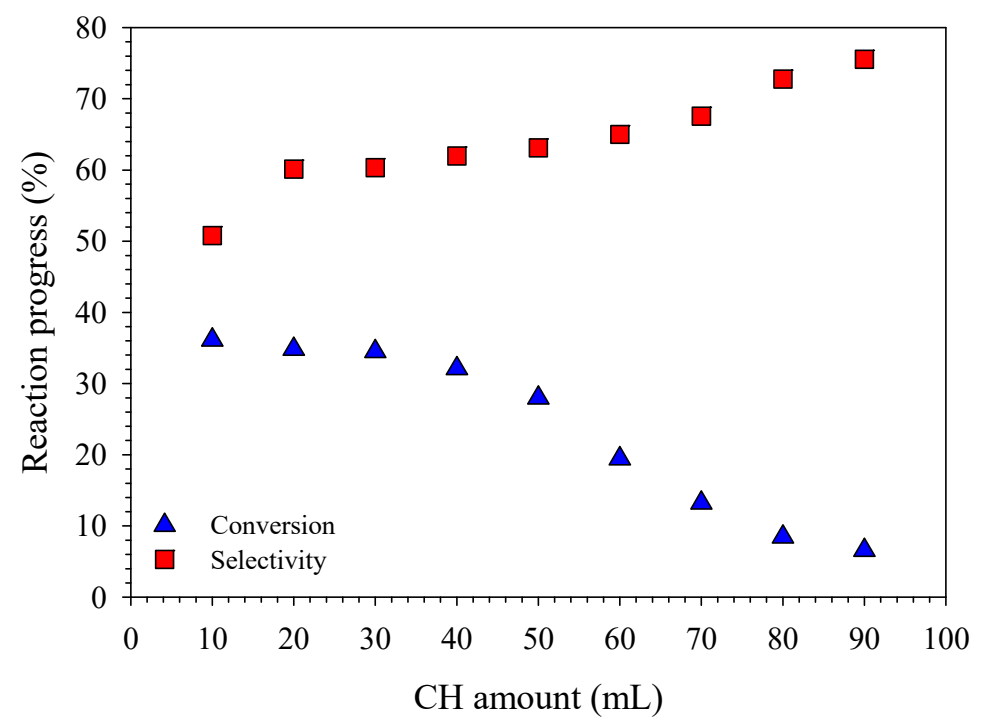

Figure 3. $\mathrm{CH}$-to- $\mathrm{COH} / \mathrm{RCOR}$ conversion as a function of ${ }^{\mathrm{a}} \mathrm{CH}$ amount. Conditions: Cat: $0.15 \mathrm{~g}, \mathrm{pO}_{2}$ : 570 Torr, duration: $210 \mathrm{~min}$, temp: $80^{\circ} \mathrm{C}$, flow rate: $40 \mathrm{~mL} / \mathrm{min}$.

Fang \& co-workers [49] performed electrocatalytic oxidation of $\mathrm{CH}$ to $\mathrm{CHOH} / \mathrm{RCOR}$ using a functional electrocatalytic membrane reactor (ECMR) assembled with an $\mathrm{MnO}$ nanostructure that was loaded on a porous titanium membrane as an anode in a ternary system of $\mathrm{CH}$, water and acetic acid. They observed the same trend in selectivity and conversion per unit time. Table 1 reflects the higher catalytic activity of $\mathrm{Mn}$-ferrite and Ca-doped $\mathrm{Mn}$-ferrite used for the oxidation of $\mathrm{CH}$ in solvent-free conditions compared to all reported catalysts being used for the oxidation of COH/RCOR [29-31,50].

Scheme $2(i-v)$ shows the oxidation of $\mathrm{CH}$ to $\mathrm{COH} / \mathrm{RCOR}$ with molecular oxygen and Mn-ferrite. The reaction was initiated by the Fe of the Mn-ferrite in the presence of molecular oxygen, while Mn shows a synergistic effect. This observation was confirmed by carrying out experiments with simple iron oxide as a catalyst under the same set of reaction conditions; we obtained the low productivity value of $101.52 \mathrm{mmolg}^{-1} \mathrm{~h}^{-1}$, which is too low in comparison to the productivity value for Mn-ferrite (366.17 mmolg $\left.{ }^{-1} \mathrm{~h}^{-1}\right)$; thus, it is confirmed that Mn has a synergistic effect on the activity of Mn-ferrite, as shown in Table 2. 
Table 1. Comparison of the catalytic activity of different catalysts being used for the oxidation of hydrocarbons.

\begin{tabular}{|c|c|c|c|c|c|}
\hline S. No & Catalyst & Reactant & Reaction Conditions & $\begin{array}{l}\text { * Productivity } \\
\left(\mathrm{mmolg}^{-1} \mathrm{~h}^{-1}\right)\end{array}$ & Ref \\
\hline 1 & Ti-MWW & ${ }^{\mathrm{b}} \mathrm{CH}$ & $\begin{array}{c}80{ }^{\circ} \mathrm{C}, 1 \mathrm{~h}, 4 \mathrm{~g} \text { of } \mathrm{CH}, 0.10 \mathrm{~g} \\
\text { of catalyst, TBHP }\end{array}$ & $50.85^{b}$ & [31] \\
\hline 2 & $\mathrm{C}_{3} \mathrm{~N}_{4} / \mathrm{Au}$ & ${ }^{\mathrm{b}} \mathrm{CH}$ & $\begin{array}{c}60^{\circ} \mathrm{C}, 24 \mathrm{~h}, 10 \mathrm{~mL} \text { of } \mathrm{CH} \text {, } \\
0.5 \mathrm{~g} \text { of catalyst, } 200 \mathrm{~mL} \\
\text { ultra-pure water, Xe-lamp }\end{array}$ & $0.812^{b}$ & [50] \\
\hline 3 & $\mathrm{MnFe}_{2} \mathrm{O}_{4}$ & ${ }^{a b c} \mathrm{CH}$ & $\begin{array}{c}80{ }^{\circ} \mathrm{C}, 3.5 \mathrm{~h}, 20 \mathrm{~mL} \text { of } \mathrm{CH}, \\
0.15 \mathrm{~g} \text { of catalyst, } \mathrm{O}_{2}\end{array}$ & $\begin{array}{l}366.17^{\mathrm{a}} \\
241.17^{\mathrm{b}} \\
219.17^{\mathrm{c}}\end{array}$ & This study \\
\hline 4 & $\mathrm{Ca}-\mathrm{MnFe}_{2} \mathrm{O}_{4}$ & ${ }^{a b c} \mathrm{CH}$ & $\begin{array}{c}80{ }^{\circ} \mathrm{C}, 3.5 \mathrm{~h}, 20 \mathrm{~mL} \text { of } \mathrm{CH}, \\
0.15 \mathrm{~g} \text { of catalyst, } \mathrm{O}_{2}\end{array}$ & $\begin{array}{l}379.38^{a} \\
285.31^{b} \\
247.31^{c}\end{array}$ & This study \\
\hline
\end{tabular}

${ }^{\mathrm{a}}$ : cyclooctane, ${ }^{\mathrm{b}}$ : cyclohexane, ${ }^{\mathrm{c}}$ : cyclohexene; $*$ Productivity $=\frac{\text { reactant converted (mmol) }}{\operatorname{Cat}(g) \times \operatorname{Time}(h)}$.

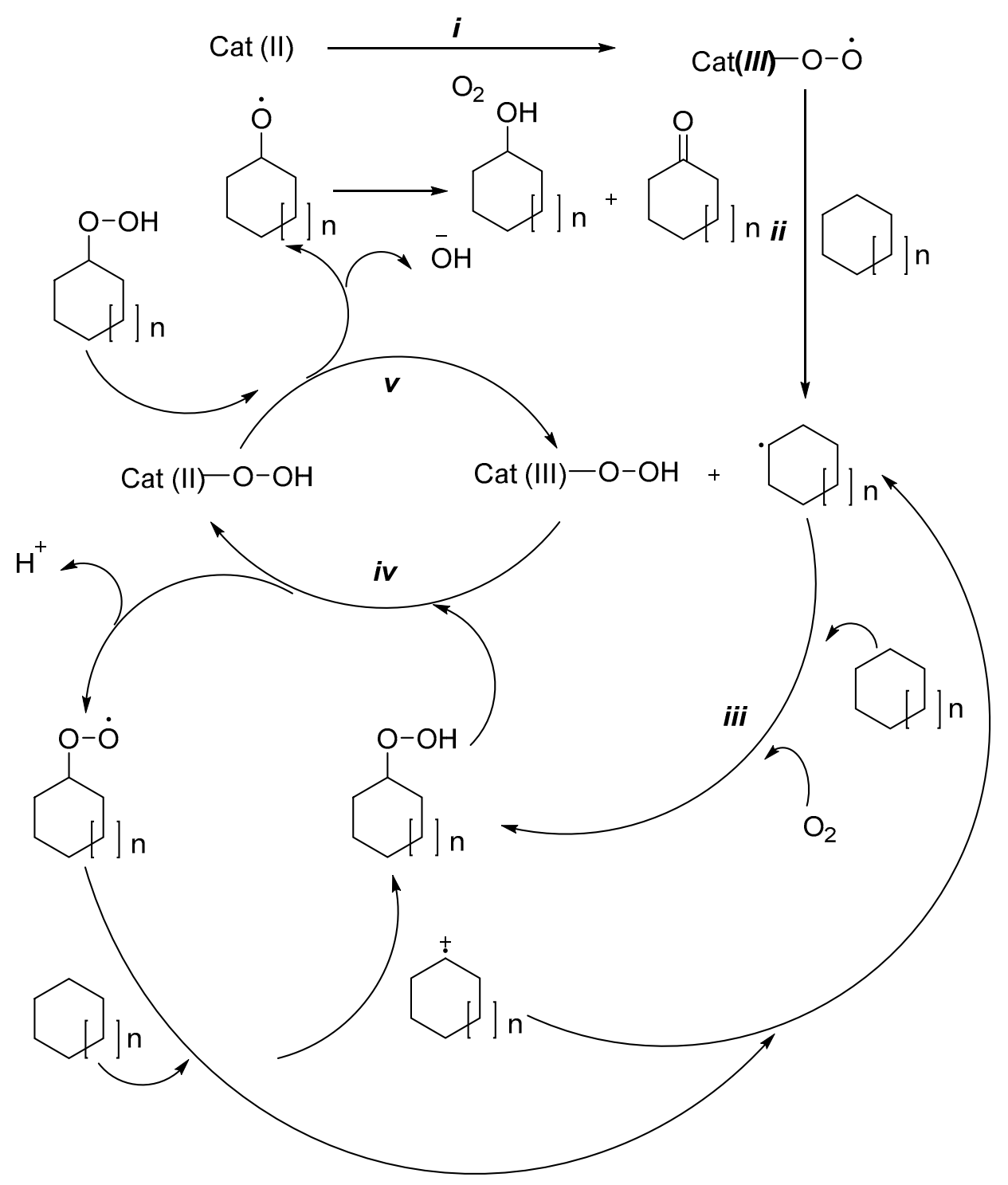

Scheme 2. Cont. 
1

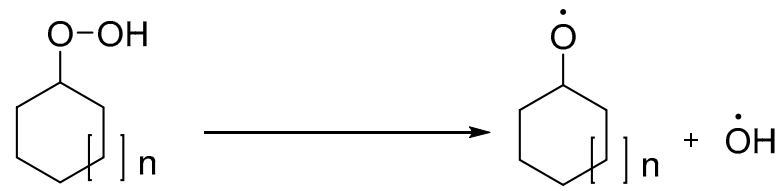

2

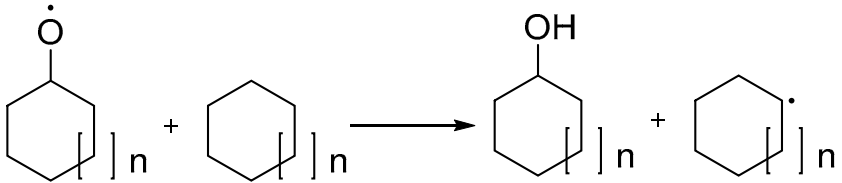

3

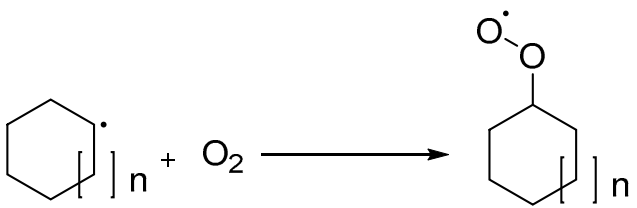

$0^{\circ}$

4

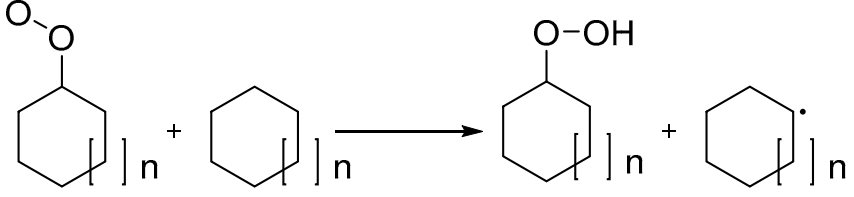

5

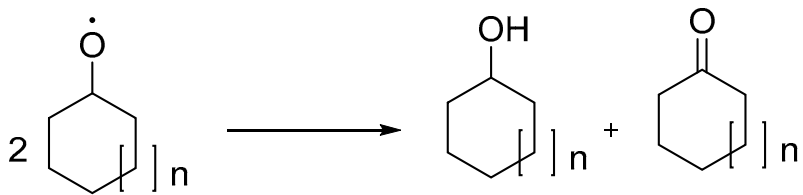

Scheme 2. Proposed mechanism for oxidation of $\mathrm{CH}$ to $\mathrm{CHOH} / \mathrm{RCOR}(\mathrm{n}=1,3)$ over $\mathrm{MnFe}_{2} \mathrm{O}_{4} /$ Ca- $\mathrm{MnFe}_{2} \mathrm{O}_{4}$ in the presence of oxygen, where step 1 ; involved dissociation of hydroperoxycyclohexane, step 2; cyclohexyl radical generation, step 3 and step 4; chain reaction for the production of cyclohexyl radical, step 5; product formation in termination reaction.

Table 2. Catalytic activity of catalysts for the oxidation of ${ }^{\mathrm{a}} \mathrm{CH}$.

\begin{tabular}{|c|c|c|c|}
\hline S. No & Catalyst & Productivity * & Synergistic Effect of Mn \\
\hline 1 & Iron oxide & 101.52 & \\
\hline 2 & $\mathrm{MnFe}_{2} \mathrm{O}_{4}$ & 366.17 & 264.65 \\
\hline 3 & $20 \%>\mathrm{Ca}-\mathrm{MnFe}_{2} \mathrm{O}_{4}$ & 379.38 & $\begin{array}{c}\text { Enhancing Effect of } \mathrm{Ca} \text { on } \mathrm{MnFe}_{2} \mathrm{O}_{4} \\
13.21\end{array}$ \\
\hline 4 & $50 \% \leq \mathrm{Ca}-\mathrm{MnFe}_{2} \mathrm{O}_{4}$ & 359.31 & $\begin{array}{c}\text { Retarding Effect of } \mathrm{Ca} \text { on } \mathrm{MnFe}_{2} \mathrm{O}_{4} \\
6.79\end{array}$ \\
\hline
\end{tabular}

Similarly, the addition of calcium to Mn-ferrite further promotes the catalytic activity of $\mathrm{MnFe}_{2} \mathrm{O}_{4}$, as presented in Table 2, while reducing the ease of the magnetic filtration of the catalyst from the reaction mixture. Hou et al. [51] reported Ca-promoted $\mathrm{Ni} / \alpha-\mathrm{Al}_{2} \mathrm{O}_{3}$ for the dry reforming of $\mathrm{CH}_{4}$ and observed that the enhancing effect of $\mathrm{Ca}$ on the catalytic activity depends on its interaction with the support material.

Theoretical calculation (DFT) shows the electronic band gap energy in the spin-up state $(1.6 \mathrm{eV})$ and spin-down state $(0.0 \mathrm{eV})$ for $\mathrm{MnFe}_{2} \mathrm{O}_{4}$. The results are comparable with the experimental band gap energy values of $\mathrm{MnFe}_{2} \mathrm{O}_{4}(1.25 \mathrm{eV})$ in the spin-up state and $(0.4 \mathrm{eV})$ in the spin-down state, respectively [51,52]. The band gap energies for Ca-Mn-ferrite in the spin-up state and spin-down state are $(2.3 \mathrm{eV})$ and $(0.0 \mathrm{eV})$, respectively. Ca doping $\geq 50 \%$, increases the band gap energy in the spin-up state of $\mathrm{MnFe}_{2} \mathrm{O}_{4}$ up to $(0.7 \mathrm{eV})$, as shown in Figure $4 \mathrm{a}$, while Ca doping up to $20 \%$ decreased the band gap energy by $0.22 \mathrm{eV}$. Ustundağ et al. [11] have also reported that the band gap energy of $\mathrm{MnFe}_{2} \mathrm{O}_{4}$ is reduced by the incorporation of calcium. The Density of States (DOS) structure of $\mathrm{MnFe}_{2} \mathrm{O}_{4}$ and 
$\mathrm{Ca}-\mathrm{MnFe}_{2} \mathrm{O}_{4}$ is presented in Figure $4 \mathrm{~b}$, which reveals that the $\mathrm{Fe}$ atom has a paramount impact on DOS structure for $\mathrm{MnFe}_{2} \mathrm{O}_{4}$; similarly, $\mathrm{Fe}$ and $\mathrm{Mn}$ atoms have a great impact, while Ca contribution is too low in the DOS structure for Ca- $\mathrm{MnFe}_{2} \mathrm{O}_{4}$. The total DOS structure of $\mathrm{MnFe}_{2} \mathrm{O}_{4}$ and Ca- $\mathrm{MnFe}_{2} \mathrm{O}_{4}$ is given in Figure 5, which shows the similar band structure in spin-down states, while the band gaps of $\mathrm{MnFe}_{2} \mathrm{O}_{4}(1.6 \mathrm{eV})$ and $\mathrm{Ca}-\mathrm{MnFe}_{2} \mathrm{O}_{4}(2.3 \mathrm{eV})$ are mainly determined by spin-up states. The total magnetic moment of the unit cell and total magnetic moment of the formula unit both decrease with the addition of $\mathrm{Ca}$ to $\mathrm{MnFe}_{2} \mathrm{O}_{4}(110.29 \mu \mathrm{B}$ to $93.63 \mu \mathrm{B})$ and $(13.78 \mu \mathrm{B}$ to $11.70 \mu \mathrm{B})$, respectively [11], as shown in Table S1, which shows close agreement with the experimental results. As represented in Scheme $2(i-v)$, the Cat (II) was activated in the presence of molecular oxygen to produce Cat (III)-OO ${ }^{\circ}$, where (II) and (III) show the oxidation states. Hydrogen was abstracted from $\mathrm{CH}$ by Cat (III)-OO ${ }^{\circ}$ and produced Cat (III)-OOH and cyclohexyl radical $\left(\mathrm{CHy}^{\bullet}\right)$, which further gave cyclohexylhydroperoxide $(\mathrm{CHHP})$ and $\mathrm{CHy}^{\bullet}$ in the presence of molecular oxygen and $\mathrm{CH}$. The cyclohexyl radical $\left(\mathrm{CHy}^{\bullet}\right)$ was recycled in the process. The cyclohexylperoxy radical was produced from the oxidation of (CHHP) by Cat (III)-OOH; a proton $\left(\mathrm{H}^{+}\right)$was eliminated to produce Cat (II)-OOH.
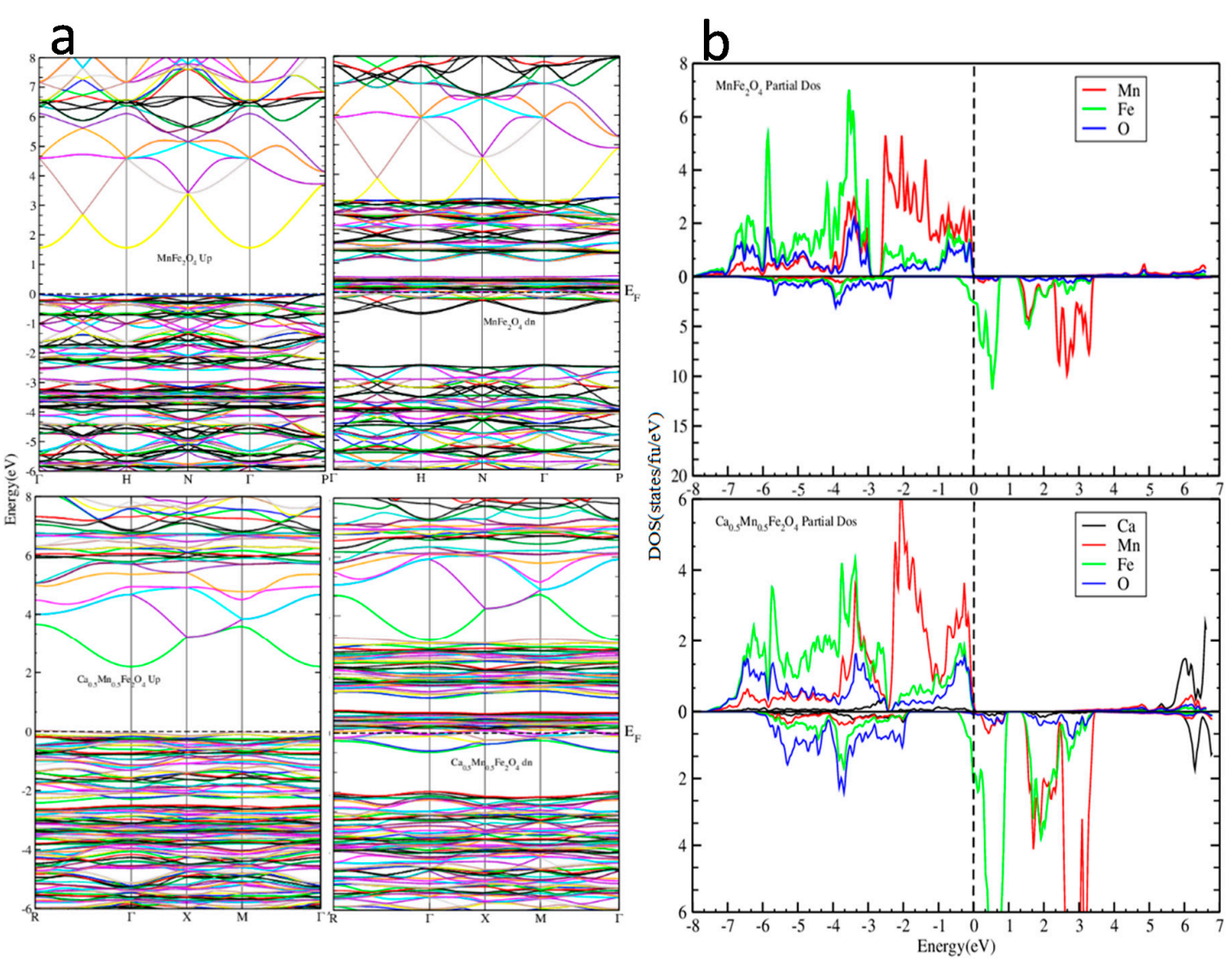

Figure 4. (a) Calculated spin-polarized band, (b) partial contribution of different atoms in the electronic structure of $\mathrm{MnFe}_{2} \mathrm{O}_{4}$ and $\mathrm{Ca}_{0.5} \mathrm{Mn}_{0.5} \mathrm{Fe}_{2} \mathrm{O}_{4}$.

However, when the cyclohexylperoxy radical was recycled, a small amount of product was obtained, which may be due to the dissolved oxygen in the reactant or the bulk oxygen of oxide catalyst. Liu \& co-workers [50] performed the oxidation of $\mathrm{CH}$ to KA oil, using $\mathrm{C}_{3} \mathrm{~N}_{4} / \mathrm{Au}$ composites, and attained low conversion $(10.54 \%)$ with high selectivity $(100 \%)$ under visible light, without using any initiator. However, in the electrocatalytic oxidation of the $\mathrm{CH}$ with a Ti membrane decorated with nano-Mn oxide, $14.6 \%$ conversion, and high selectivity of $99.8 \%$ was obtained [49]. Similarly, Ti-containing zeolite catalysts were also efficiently used for oxidation of $\mathrm{CH}$ with $90 \%$ selectivity [31]. In the reported studies [31,49,50], the achieved \% conversion was very poor and the method of preparation of the catalyst was also expensive; therefore, Mn-ferrite and Ca-Mn-ferrite are active, affordable, and efficient catalysts for the oxidation of $\mathrm{CH}$ and might be a good alternative for industrial use. 

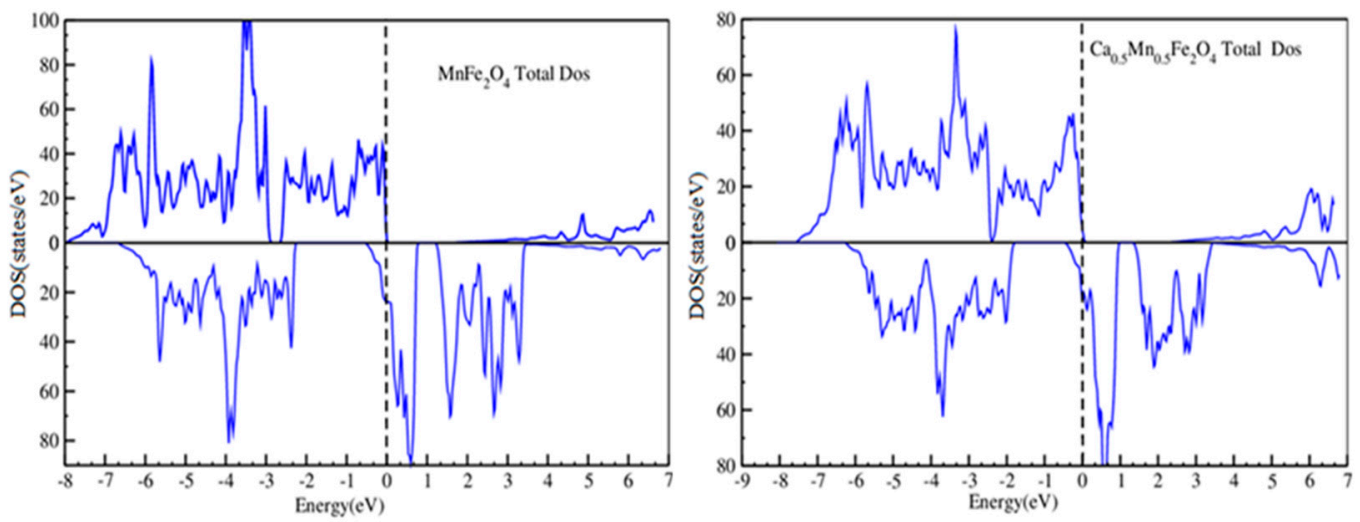

Figure 5. The total density of states for spin-up and spin-down states of $\mathrm{MnFe}_{2} \mathrm{O}_{4}$ and Ca-doped $\mathrm{MnFe}_{2} \mathrm{O}_{4}$ compound.

\subsection{Kinetics Studies}

\subsubsection{Effect of Oxygen Partial Pressure}

Figure 6 shows the kinetics of a model reaction where (Figure 6a) represents the effect of oxygen partial pressure on the conversion of $\mathrm{CH}$. An increase in oxygen partial pressure is accompanied by an increase in the rate of conversion up to $\mathrm{pO}_{2} \approx 570$ Torr. A further increase in $\mathrm{pO}_{2}$ did not show any enhancing effect but, instead, a small reduction in the rate of reaction was observed. To obtain the mechanism of surface reaction (between oxygen and $\mathrm{CH}$ ), various reaction rate equations were carried out [53] based upon the Langmuir-Hinshelwood (LH) mechanism, the Eley-Rideal (ER) mechanism and the Mars-van Kreveleen mechanism.
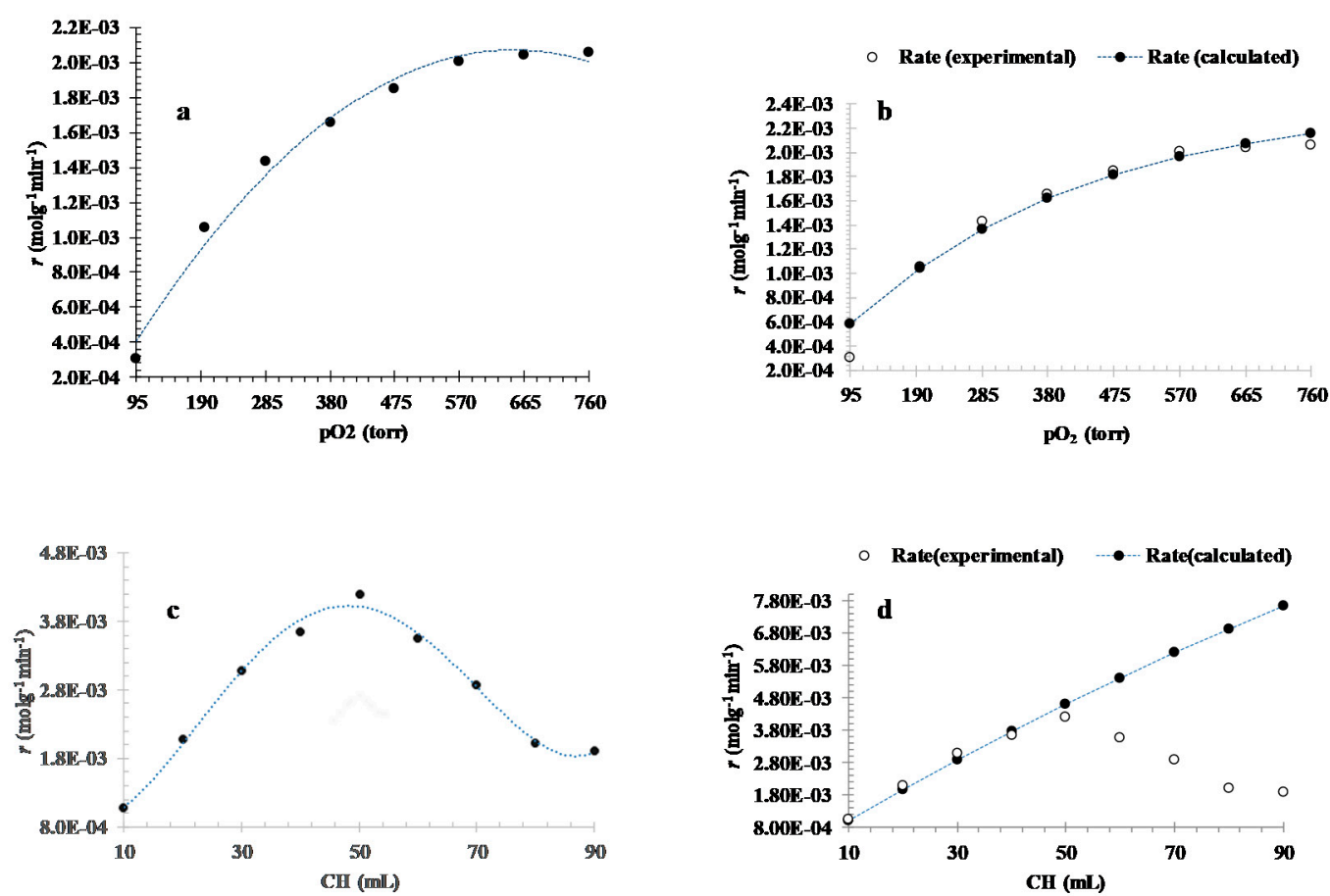

Figure 6. Kinetics of $\mathrm{CH}$ oxidation (a); effect of oxygen partial pressure on the rate of $\mathrm{CH}$ conversion using a $\mathrm{MnFe}_{2} \mathrm{O}_{4}$ catalyst, (b); comparison of experimental and calculated rates from non-linear least-square fit for oxygen partial pressure, (c); effect of change in $\mathrm{CH}$ volume on the rate of reaction, (d); correlation between experimental and calculated rates for $\mathrm{CH}$ volume. 
The data did not fit into equations based upon the ER and MK Mechanisms. The LangmuirHinshelwood mechanism is based upon the reaction of the reactant in an adsorbed state. However, as it is a solvent-free reaction, the $\mathrm{CH}$ concentration remains constant and the rate only depends on the amount of oxidant. Various adsorption isotherm equations for the representation of $\theta_{\mathrm{O}_{2}}$ were used, including the Langmuir adsorption isotherm for non-dissociative and dissociative adsorption of oxygen, te Temkin isotherm and the Freundlich isotherm. However, none of these equations resulted in a better fit than the Langmuir equation for competitive adsorption.

The equation for competitive adsorption between oxygen $\left(\mathrm{O}_{2}\right)$ and $\mathrm{CH}$ on a surface can be represented as:

$$
\begin{gathered}
\text { Surface covered by } \mathrm{O}_{2}, \theta_{\mathrm{O}_{2}}=\frac{K_{\mathrm{O}_{2}} p_{\mathrm{O}_{2}}}{1+K_{\mathrm{CH}} C_{\mathrm{CH}}+K_{\mathrm{O}_{2}} p_{\mathrm{O}_{2}}} \\
\text { Surface covered by } \mathrm{CH}, \theta_{\mathrm{CH}}=\frac{K_{\mathrm{CH}} C_{\mathrm{CH}}}{1+K_{\mathrm{CH}} C_{\mathrm{CH}}+K_{\mathrm{O}_{2}} p_{\mathrm{O}_{2}}} \\
\text { Therefore, rate of reaction }=\mathrm{k}_{\mathrm{r}} \theta_{\mathrm{CH}} \theta \mathrm{O}_{2}=\frac{k_{r} K_{\mathrm{CH}} C_{\mathrm{CH} K_{\mathrm{O}_{2}} p_{\mathrm{O}_{2}}}}{\left(1+K_{\mathrm{CH}} C_{\mathrm{CH}}+K_{\mathrm{O}_{2}} p_{\mathrm{O}_{2}}\right)^{2}} .
\end{gathered}
$$

For studying the effect of oxygen partial pressure at a constant $\mathrm{CH}$ concentration, Equation (3) is modified to be suitable for using the nonlinear least-square program (Curve Expert 1.4) in the following form (Equation (4)):

$$
\text { Rate }=\frac{a * b * c p_{\mathrm{O}_{2}}}{\left(1+b+c p_{\mathrm{O}_{2}}\right)^{2}}
$$

where $a=k_{r}, b=\mathrm{K}_{\mathrm{CH}} \mathrm{C}_{\mathrm{CH}}$ and $c=\mathrm{K}_{\mathrm{O} 2}$.

Using Equation (4), the best fit was obtained, as shown in Figure $6 b$, while the comparison of experimental data points and the calculated data points using the constants $a, b$, and $c$ was obtained. The values of the constants were used for the rate calculation at various oxygen partial pressures. The correlation coefficient $R^{2}$ was 0.982 , which is reasonably better than all other rate equations applied for oxygen partial pressure effects in this case.

\subsubsection{Effect of Initial Substrate Volume}

It is a solvent-free reaction and, therefore, the concentration of $\mathrm{CH}$ would remain constant and, so, normally, surface coverage for $\mathrm{CH}$ should remain constant, whatever the volume of $\mathrm{CH}$ may be. However, Figure $6 \mathrm{c}$ shows that, practically, the rate of reaction changes with a change in the volume of $\mathrm{CH}$. Rate increases up to a maximum at $50 \mathrm{~mL}$ of $\mathrm{CH}$, after which it rapidly decreases. In a competitive adsorption between two reactants at the surface, an increase in the concentration of one reactant increases the surface coverage and simultaneously decreases the surface coverage of another reactant; as a result, the rate of reaction increases and the maximum rate is achieved at a point where the surface coverage of the reactants becomes equal. A further increase in the concentration of either reactant would decrease the rate of reaction, as shown in Figure $6 c$, as the decline in the rate of reaction is much faster when the volume of $\mathrm{CH}$ is increased above $50 \mathrm{~mL}$. This could be due to the fact that the volume of $\mathrm{CH}$ affects the surface concentration of $\mathrm{O}_{2}\left(\theta_{\mathrm{O}_{2}}\right)$. As a competitive adsorption, any reduction in the surface coverage of $\mathrm{O}_{2}$ would increase the surface coverage of $\mathrm{CH}$ and, therefore, a change in the rate of reaction occurs. Thus, the equation for competitive adsorption was applied to the data where the concentration of $\mathrm{CH}\left(\mathrm{C}_{\mathrm{CH}}\right)$ was replaced by $\mathrm{V}_{\mathrm{CH}}$, as shown in Equation (5).

$$
\text { Rate }=k_{r} \theta_{\mathrm{CH}} \theta_{\mathrm{O}_{2}}=\frac{k_{r} K_{\mathrm{CH}} V_{\mathrm{CH}} K_{\mathrm{O}_{2}} p_{\mathrm{O}_{2}}}{\left(1+K_{\mathrm{CH}} C V_{\mathrm{CH}}+K_{\mathrm{O}_{2}} p_{\mathrm{O}_{2}}\right)^{2}}
$$

This equation (Equation (5)) was applied for calculating the rate of reaction as a function of the volume of $\mathrm{CH}$. All of the constants obtained from Figure $6 \mathrm{~b}$ were used as such. However, the constant 
$b\left(=\mathrm{K}_{\mathrm{CH}} \mathrm{C}_{\mathrm{CH}}\right)$ was used as " $\mathrm{K}_{\mathrm{CH}} \mathrm{V}_{\mathrm{CH}}$ ". Figure $6 \mathrm{~b}$ has a constant volume of $\mathrm{CH}(20 \mathrm{~mL})$; therefore, $\mathrm{K}_{\mathrm{CH}}$ was obtained by as $b / \mathrm{V}_{\mathrm{CH}}\left(=1.55 \mathrm{E}^{-3} / \mathrm{mL}\right)$. The experimental and calculated rates as a function of the volume of $\mathrm{CH}$ are shown in Figure 6d. There is an excellent correlation between experimental and calculated rates for $\mathrm{CH}$ volume $\leq 50 \mathrm{~mL}$. For volume $\geq 60 \mathrm{~mL}$, there is a very rapid reduction in the rate of reaction. Attempts to apply the equation of competitive adsorption to the whole data $(10-90 \mathrm{~mL}$ of $\mathrm{CH})$ using the non-linear least-square fit was unsuccessful.

Only rates that were obtained for $\mathrm{V}_{\mathrm{CH}} \leq 50$ show a similar plot, as shown in Figure $6 \mathrm{~d}$, with the constants obtained having similar values, as obtained in Figure $6 \mathrm{~b}$. The change in the rate of reaction with a change in the volume of $\mathrm{CH}$ could be due to the effect of volume change on the rate of transportation of oxygen to the catalyst surface. With the increase in volume, there is a reduction in the rate of diffusion of oxygen to the catalyst surface. This reduction in the rate of diffusion of oxygen to the catalyst surface is still faster than the rate of adsorption/reaction/desorption up to $\mathrm{V}_{\mathrm{CH}}=50 \mathrm{~mL}$. However, at $\mathrm{V}_{\mathrm{CH}} \geq 60 \mathrm{~mL}$, the rate of diffusion of oxygen to the catalyst surface becomes slower than the surface reactions, and the reaction becomes diffusion controlled. One reason could be that the kinetic equation is applicable only in the kinetically controlled region $(\leq 50 \mathrm{~mL})$. Activation energy $(82.54 \mathrm{~kJ} / \mathrm{mol})$ was calculated from the Arrhenius plot shown in Figure 7. Bavykin et al. [54] have reported activation energy $=79 \mathrm{~kJ} / \mathrm{mol}$ in a purely kinetic regime. An activation energy $=77.8 \mathrm{~kJ} / \mathrm{mol}$ was also considered in a free-mass transfer zone [53]. Thus, the activation energy in the present case shows that, in these conditions, the reaction is free of mass transfer and is in good agreement with kinetic studies.

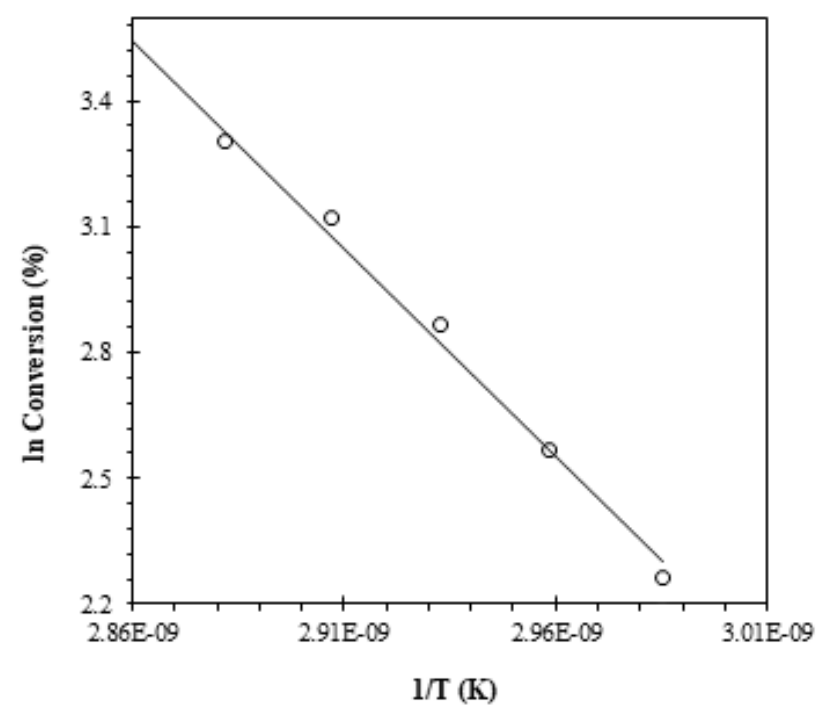

Figure 7. Activation energy calculated from Arrhenius plot for oxidation of $\mathrm{CH}$. Conditions: Cat: 0.15 g, vol: $20 \mathrm{~mL}, \mathrm{pO}_{2}: 570$ Torr, time: $210 \mathrm{~min}$, temp: $60-80^{\circ} \mathrm{C}$, flow rate: $40 \mathrm{~mL} / \mathrm{min}$.

\subsubsection{Separation and Recyclability of $\mathrm{MnFe}_{2} \mathrm{O}_{4}$}

To confirm the heterogeneity of the catalysts, a series of experiments was carried out. In the first run, $20 \mathrm{~mL}$ reactant was loaded under the optimal set of parameters. The product was determined by iodometry and GC analysis. The catalyst was recycled five times with a stable catalytic activity in the oxidation of $\mathrm{CH}$, as shown in Figure 8a. The magnetic nanoparticles were successfully separated from the reaction medium by using an external magnet, as shown in Figure 8b. The extended life span is an important feature for industrial catalysis. 


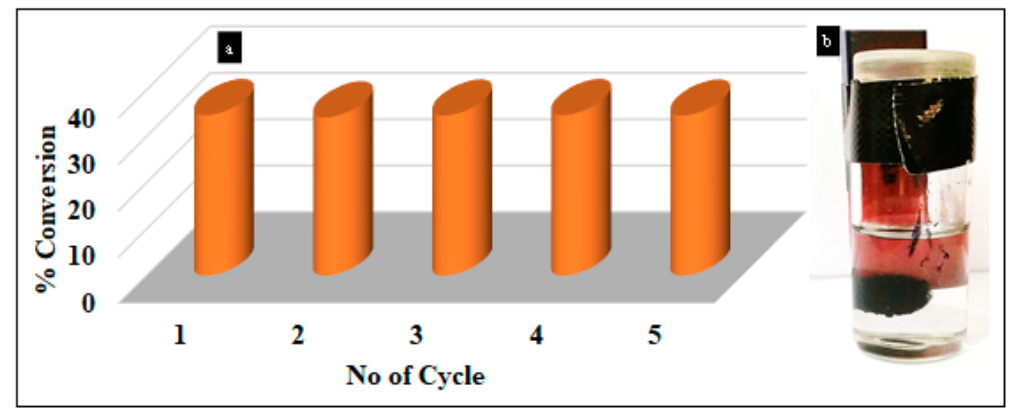

Figure 8. (a) Reuse of the catalyst, (b) separation of the catalyst from reaction medium. Conditions: Cat: $0.15 \mathrm{~g}$, vol: $20 \mathrm{~mL}, \mathrm{pO}_{2}$ : 570 Torr, time: $210 \mathrm{~min}$, temp: $80^{\circ} \mathrm{C}$, flow rate: $40 \mathrm{~mL} / \mathrm{min}$.

\section{Conclusions}

The catalysts (Mn-ferrite and Ca-doped Mn-ferrite) were efficiently used for the synthesis of $\mathrm{COH} / \mathrm{RCOR}$ from the oxidation of $\mathrm{CH}$ in the presence of molecular oxygen under solvent-free conditions in a self-designed reactor (GBR reactor). The catalyst shows good productivity values of 366.17 and $379.38 \mathrm{mmolg}^{-1} \mathrm{~h}^{-1}$ for Mn-ferrite and Ca-Mn-ferrite, respectively, at optimal conditions. The synergetic effect of Ca doping on the catalytic activity of $\mathrm{MnFe}_{2} \mathrm{O}_{4}$ was theoretically explored and corelated with experimental observations. The only discrepancy of Ca doping was reducing the magnetic properties of $\mathrm{MnFe}_{2} \mathrm{O}_{4}$. Furthermore, the reaction shows no mass transfer effect and it follows the Langmuir-Hinshelwood mechanism for the competitive adsorption of $\mathrm{CH}$ and oxygen. These catalysts are truly heterogenous with extended life spans and will be a green alternative to existing industrial processes.

Supplementary Materials: The following are available online at http://www.mdpi.com/2073-4352/10/4/335/s1, Figure S1: Calibration curve of $\mathrm{CH}$ in a mixture solution of $\mathrm{CHOH}$ and $\mathrm{RCOR}$, Figure S2: Calibration curve of $\mathrm{COH}$ in a mixture solution of $\mathrm{CH}$ and RCOR, Figure S3: Calibration curve of RCOR in a mixture solution of $\mathrm{CH}$ and $\mathrm{COH}$, Figure S4: EDX spectrum of $\mathrm{MnFe}_{2} \mathrm{O}_{4}$, Table S1: Magnetic moment for Mn-ferrite and Ca-Mn-ferrite.

Author Contributions: Z.I. and S.S. carried out the research, M.S. was the PI of the project, M.A. edited the initial draft, K.S. and N.U.R. characterized the catalyst, M.I. preformed kinetic calculation. S.U., S.U.J. and I.A. performed the computational studies, M.H.S. help in the editing and reviewing. All authors have read and agreed to the published version of the manuscript.

Funding: This research was funded by the Higher Education Commission of Pakistan.

Acknowledgments: The authors greatly acknowledge the financial support of the Higher Education Commission of Pakistan, the Pakistan Science Foundation and the University of Malakand.

Conflicts of Interest: The authors declare no conflict of interest.

\section{References}

1. Zhenyu, L.; Guangliang, X.; Yalin, Z. Microwave assisted low temperature synthesis of MnZn ferrite nanoparticles. Nanoscale Res. Lett. 2007, 2, 40. [CrossRef]

2. Koleva, K.V.; Velinov, N.I.; Tsoncheva, T.S.; Mitov, I.G.; Kunev, B.N. Preparation, structure and catalytic properties of $\mathrm{ZnFe}_{2} \mathrm{O}_{4}$. Bulg. Chem. Commun. 2013, 45, 434-439.

3. Chavan, A.R.; Birajdar, S.D.; Chilwar, R.R.; Jadhav, K.M. Structural, morphological, optical, magnetic and electrical properties of $\mathrm{Al}^{3+}$ substituted nickel ferrite thin films. J. Alloys Compd. 2018, 735, 2287-2297. [CrossRef]

4. Devi, E.C.; Soibam, I. Structural and optical characterization of $\mathrm{MnFe}_{2} \mathrm{O}_{4}$ nanoparticles. Adv. Mater. Proc. 2017, 2, 93-96. [CrossRef]

5. Hassandoost, R.; Pouran, S.R.; Khataee, A.; Orooji, Y.; Joo, S.W. Hierarchically structured ternary heterojunctions based on $\mathrm{Ce}^{3+} / \mathrm{Ce}^{4+}$ modified $\mathrm{Fe}_{3} \mathrm{O}_{4}$ nanoparticles anchored onto graphene oxide sheets as magnetic visible-light-active photocatalysts for decontamination of oxytetracycline. J. Hazard. Mater. 2019, 376, 200-211. [CrossRef] [PubMed] 
6. Ullah, Z.; Atiq, S.; Naseem, S. Influence of $\mathrm{Pb}$ doping on structural, electrical and magnetic properties of Sr-hexaferrites. J. Alloys Compd. 2013, 555, 263-267. [CrossRef]

7. Tatarchuk, T.R.; Paliychuk, N.D.; Bououdina, M.; Al-Najar, B.; Pacia, M.; Macyk, W.; Shyichuk, A. Effect of cobalt substitution on structural, elastic, magnetic and optical properties of zinc ferrite nanoparticles. J. Alloys Compd. 2018, 15, 1256-1266. [CrossRef]

8. Monsef, K.Z.; Najafi, N. Magnetic solid-phase extraction to preconcentrate trace amounts of gold (III) using nickel ferrite magnetic nanoparticles. Int. J. Environ. Anal. Chem. 2017, 97, 1237-1252. [CrossRef]

9. Joshi, S.; Kumar, M.; Chhoker, S.; Srivastava, G.; Jewariya, M.; Singh, V.N. Structural, magnetic, dielectric and optical properties of nickel ferrite nanoparticles synthesized by co-precipitation method. J. Mol. Struct. 2014, 1076, 55-62. [CrossRef]

10. Lu, H.C.; Chang, J.E.; Vong, W.W.; Chen, H.T.; Chen, Y.L. Porous ferrite synthesis and catalytic effect on benzene degradation. Int. J. Phys. Sci. 2011, 6, 855-865.

11. Ustundağ, M.; Aslan, M. Electronic and Magnetic Properties of Ca-Doped Mn-Ferrite. Acta Phys. Pol. A 2016, 130, 362-364. [CrossRef]

12. Perumal, S.L.; Hemalatha, P.; Alagara, M.; Pandiyaraj, K.N. Investigation of structural, optical and photocatalytic properties of Sr doped Zno nanoparticles. Int. J. Phys. Sci. 2015, 4, 1-13.

13. Kuo, S.L.; Wu, N.L. Electrochemical characterization on $\mathrm{MnFe}_{2} \mathrm{O}_{4} /$ carbon black composite aqueous supercapacitors. J. Power Sources 2006, 162, 1437-1443. [CrossRef]

14. Menini, L.; Pereira, M.C.; Parreira, L.A.; Fabris, J.D.; Gusevskaya, E.V. Cobalt-and manganese-substituted ferrites as efficient single-site heterogeneous catalysts for aerobic oxidation of monoterpenic alkenes under solvent-free conditions. J. Catal. 2008, 254, 355-364. [CrossRef]

15. Valdés, S.T.; Valle, P.; Alvarez, S.; Marbán, G.; Fuertes, A.B. Manganese ferrite nanoparticles synthesized through a nanocasting route as a highly active Fenton catalyst. Catal. Commun. 2007, 8, 2037-2042. [CrossRef]

16. Zhang, Y.; Elfman, M.; Winzell, T.; Whitlow, H.J. Characterisation of ferromagnetic magnetic storage media surfaces by complementary particle induced X-ray analysis and time of flight-energy dispersive elastic recoil detection analysis. Nucl. Instrum. Methods Physics Res. Sect. B Beam Interact. Mater. At. 1999, 150, 548-553. [CrossRef]

17. Xiao, H.M.; Liu, X.M.; Fu, S.Y. Synthesis, magnetic and microwave absorbing properties of core-shell structured $\mathrm{MnFe}_{2} \mathrm{O}_{4} / \mathrm{TiO}_{2}$ nanocomposites. Compos. Sci. Technol. 2006, 66, 2003-2008. [CrossRef]

18. Rocha, S.T.A. Sensors and biosensors based on magnetic nanoparticles. Trac Trend Anal. Chem. 2014, 62, 28-36. [CrossRef]

19. Shah, S.; Asdi, M.H.; Hashmi, M.U.; Umar, M.F.; Awan, S.U. Thermo-responsive copolymer coated $\mathrm{MnFe}_{2} \mathrm{O}_{4}$ magnetic nanoparticles for hyperthermia therapy and controlled drug delivery. Mater. Chem. Phys. 2012, 137, 365-371. [CrossRef]

20. Chen, G.; Wang, J.; Zhou, L.; Ma, W.; Zhang, D.; Ren, F.; Yan, H.; Qiu, G.; Liu, X. A facile solvothermal synthesis and magnetic properties of $\mathrm{MnFe}_{2} \mathrm{O}_{4}$ spheres with tunable sizes. J. Am. Ceram. Soc. 2012, 95, 3569-3576. [CrossRef]

21. Alves, C.R.; Aquino, R.; Depeyrot, J.; Tourinho, F.A.; Dubois, E.; Perzynski, R. Superparamagnetic relaxation evidences large surface contribution for the magnetic anisotropy of $\mathrm{MnFe}_{2} \mathrm{O}_{4}$ nanoparticles of ferrofluids. J. Mater. Sci. 2007, 42, 2297-2303. [CrossRef]

22. Dolgykh, L.Y.; Stolyarchuk, I.L.; Vasylenko, I.V.; Pyatnitsky, Y.I.; Strizhak, P.E. Influence of the Composition of Nanosized $\mathrm{MFe}_{2} \mathrm{O}_{4}$ Spinels $(\mathrm{M}=\mathrm{Ni}, \mathrm{Co}, \mathrm{Mn})$ on Their Catalytic Properties in the Steam Reforming of Ethanol. Theor. Exp. Chem. 2013, 1, 185-192. [CrossRef]

23. Sahoo, B.; Sahu, S.K.; Nayak, S.; Dhara, D.; Pramanik, P. Fabrication of magnetic mesoporous manganese ferrite nanocomposites as efficient catalyst for degradation of dye pollutants. Catal. Sci. Technol. 2012, 2, 1367-1374. [CrossRef]

24. Dossumov, K.; Yergazieva, G.Y.; Myltykbaieva, L.K.; Asanov, N.A. Effect of Co, Ce, and La Oxides as Modifying Additives on the Activity of an $\mathrm{NiO} / \gamma-\mathrm{Al}_{2} \mathrm{O}_{3}$ Catalyst in the Oxidation of Methane to Give Synthesis Gas. Theor. Exp. Chem. 2016, 52, 119-122. [CrossRef]

25. Zakharchenko, N.I. Catalytic Properties of the $\mathrm{Fe}_{2} \mathrm{O}_{3}-\mathrm{MnO}$ System for Ammonia Oxidation. Kinet. Catal. 2001, 42, 679-685. [CrossRef]

26. Lou, J.C.; Tu, Y.J. Incinerating volatile organic compounds with ferrospinel catalyst $\mathrm{MnFe}_{2} \mathrm{O}_{4}$ : An example with isopropyl alcohol. J. Air Waste Manag. 2005, 55, 1809-1815. [CrossRef] 
27. Chen, J.; Wen, W.; Kong, L.; Tian, S.; Ding, F.; Xiong, Y. Magnetically separable and durable $\mathrm{MnFe}_{2} \mathrm{O}_{4}$ for efficient catalytic ozonation of organic pollutants. Ind. Eng. Chem. Res. 2014, 53, 6297-6306. [CrossRef]

28. Xu, B.; Bhawe, Y.; Davis, M.E. Spinel metal oxide-alkali carbonate-based, low-temperature thermochemical cycles for water splitting and $\mathrm{CO}_{2}$ reduction. Chem. Mater. 2013, 25, 1564-1571. [CrossRef]

29. Martins, N.; Martins, L.; Amorim, C.; Amaral, V.; Pombeiro, A. Solvent-free microwave-induced oxidation of alcohols catalyzed by ferrite magnetic nanoparticles. Catalysts 2017, 7, 222. [CrossRef]

30. Bhat, P.B.; Bhat, B.R. Magnetically retrievable nickel hydroxide functionalised $\mathrm{A} \mathrm{Fe}_{2} \mathrm{O}_{4}(\mathrm{~A}=\mathrm{Mn}, \mathrm{Ni})$ spinel nanocatalyst for alcohol oxidation. Appl. Nanosci. 2016, 6, 425-435. [CrossRef]

31. Zhou, W.J.; Wischert, R.; Xue, K.; Zheng, Y.T.; Albela, B.; Bonneviot, L.; Clacens, J.M.; De, C.F.; Pera, T.M.; $\mathrm{Wu}, \mathrm{P}$. Highly selective liquid-phase oxidation of cyclohexane to KA oil over Ti-MWW catalyst: Evidence of formation of oxyl radicals. ACS Catal. 2013, 4, 53-62. [CrossRef]

32. Ramanathan, A.; Hamdy, M.S.; Parton, R.; Maschmeyer, T.; Jansen, J.C.; Hanefeld, U. Co-TUD-1 catalysed aerobic oxidation of cyclohexane. Appl. Catal. A Gen. 2009, 355, 78-82. [CrossRef]

33. Lü, G.; Zhao, R.; Qian, G.; Qi, Y.; Wang, X.; Suo, J. A highly efficient catalyst Au/MCM-41 for selective oxidation cyclohexane using oxygen. Catal. Lett. 2004, 97, 115-118. [CrossRef]

34. Schuchardt, U.; Cardoso, D.; Sercheli, R.; Pereira, R.; Da Cruz, R.S. Cyclohexane oxidation continues to be a challenge. Appl. Catal. A Gen. 2001, 211,1-17. [CrossRef]

35. George, K.; Sugunan, S. Catalytic oxidation of cyclohexane over Cu-Zn-Cr ternary spinel systems. React. Kinet. Catal. Lett. 2008, 94, 253. [CrossRef]

36. Rana, R.K.; Viswanathan, B. Mo incorporation in MCM-41 type zeolite. Catal. Lett. 1998, 52, 25-29. [CrossRef]

37. Liu, Y.; Tsunoyama, H.; Akita, T.; Xie, S.; Tsukuda, T. Aerobic oxidation of cyclohexane catalyzed by size-controlled Au clusters on hydroxyapatite: Size effect in the sub-2 nm regime. ACS Catal. 2010, 1, 2-6. [CrossRef]

38. Jhansi, M.; Kishore, L.; Kumar, A. Heteronuclear macrocyclinc iron-copper complex catalyst covalently bonded to modified alumina catalyst for oxidation of cyclohexane. Int. Eng. Chem. Res. 2007, 46, 4787-4798.

39. Zhu, K.; Hu, J.; Richards, R. Aerobic oxidation of cyclohexane by gold nanoparticles immobilized upon mesoporous silica. Catal. lett. 2005, 100, 195-199. [CrossRef]

40. Ebadi, A.; Safari, N.; Peyrovi, M.H. Aerobic oxidation of cyclohexane with $\gamma$-alumina supported metallophthalocyanines in the gas phase. Appl. Catal. A Gen. 2007, 321, 135-139. [CrossRef]

41. Da Cruz, R.S.; Silva, J.M.; Arnold, U.; Schuchardt, U. Catalytic activity and stability of a chromium containing silicate in liquid phase cyclohexane oxidation. J. Mol. Cat. A Chem. 2001, 171, 251-257. [CrossRef]

42. Aijun, H.; Juanjuan, L.; Mingquan, Y.; Yan, L.; Xinhua, P. Preparation of nano- $\mathrm{MnFe}_{2} \mathrm{O}_{4}$ and its catalytic performance of thermal decomposition of ammonium perchlorate. Chin. J. Chem. Eng. 2011, 19, 1047-1051.

43. Blaha, P.; Schwarz, K.; Madsen, G.K.; Kvasnicka, D.; Luitz, J. WIEN2K, an Augmented Plane Wave+ Local Orbitals Program for Calculating Crystal Properties; Vienna University of Technology: Vienna, Austria, 2001.

44. Tran, F.; Blaha, P. Accurate band gaps of semiconductors and insulators with a semilocal exchange-correlation potential. Phys. Rev. Lett. 2009, 102, 226401. [CrossRef]

45. Bellusci, M.; La, B.A.; Seralessandri, L.; Padella, F.; Piozzi, A.; Varsano, F. Preparation of albumin-ferrite superparamagnetic nanoparticles using reverse micelles. Polym. Int. 2009, 58, 142-147. [CrossRef]

46. Rodionova, L.I.; Smirnov, A.V.; Borisova, N.E.; Khrustalev, V.N.; Moiseeva, A.A.; Grünert, W. Binuclear cobalt complex with Schiff base ligand: Synthesis, characterization and catalytic properties in partial oxidation of cyclohexane. Inorg. Chim. Acta. 2012, 392, 221-228. [CrossRef]

47. Vignesh, R.H.; Sankar, K.V.; Amaresh, S.; Lee, Y.S.; Selvan, R.K. Synthesis and characterization of $\mathrm{MnFe}_{2} \mathrm{O}_{4}$ nanoparticles for impedometric ammonia gas sensor. Sens. Actuators B Chem. 2015, 220, 50-58. [CrossRef]

48. Kooti, M.; Sedeh, A.N. Glycine-assisted fabrication of zinc and manganese ferrite nanoparticles. Sci. Iran. 2012, 19, 930-933. [CrossRef]

49. Fang, X.; Yin, Z.; Wang, H.; Li, J.; Liang, X.; Kang, J.; He, B. Controllable oxidation of cyclohexane to cyclohexanol and cyclohexanone by a nano-MnOx/Ti electrocatalytic membrane reactor. J. Catal. 2015, 329, 187-194. [CrossRef]

50. Liu, J.; Yang, Y.; Liu, N.; Liu, Y.; Huang, H.; Kang, Z. Total photocatalysis conversion from cyclohexane to cyclohexanone by $\mathrm{C}_{3} \mathrm{~N}_{4} / \mathrm{Au}$ nanocomposites. Green Chem. 2014, 16, 4559-4565. [CrossRef]

51. Hou, Z.; Yokota, O.; Tanaka, T.; Yashima, T. Characterization of Ca-promoted $\mathrm{Ni} / \alpha-\mathrm{Al}_{2} \mathrm{O}_{3}$ catalyst for $\mathrm{CH}_{4}$ reforming with $\mathrm{CO}_{2}$. Appl. Catal. A Gen. 2003, 253, 381-387. [CrossRef] 
52. Rizvi, S.B.; Yildirimer, L.; Ghaderi, S.; Ramesh, B.; Seifalian, A.M.; Keshtgar, M. A novel POSS-coated quantum dot for biological application. Int. J. Nanomed. 2012, 7, 3915-3927.

53. Ilyas, M.; Sadiq, M. Liquid-Phase Aerobic Oxidation of Benzyl Alcohol Catalyzed by Pt/ZrO 2 . Chem. Eng. Technol. 2007, 30, 1391-1397. [CrossRef]

54. Bavykin, D.V.; Lapkin, A.A.; Plucinski, P.K.; Friedrich, J.M.; Walsh, F.C. $\mathrm{TiO}_{2}$ nanotube-supported ruthenium (III) hydrated oxide: A highly active catalyst for selective oxidation of alcohols by oxygen. J. Catal. 2005, 235, 10-17. [CrossRef]

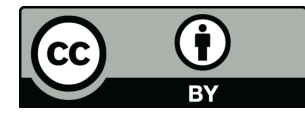

(C) 2020 by the authors. Licensee MDPI, Basel, Switzerland. This article is an open access article distributed under the terms and conditions of the Creative Commons Attribution (CC BY) license (http://creativecommons.org/licenses/by/4.0/). 